\title{
Impact of leisure environmental supply on new urban pathology: a case study of Guangzhou and Zhuhai
}

Yi Liu (10 ${ }^{1 \times}$, Congping $\mathrm{Li}^{1} \&$ Yuan $\mathrm{Li}^{1}$

Traditional studies on urban pathology primarily focused on impacts of social disorganization and urban settings, such as crime, polarization between the rich and the poor, pollution, and deteriorating living conditions, whereas there is insufficient attention paid to urban mental health and wellness. To provide fresh insights into the issue of urban mental health and wellness, this paper defines the psychiatric disorder of urban citizens as 'new urban pathology' which primarily results from a highly competitive, stressful, and fast-paced urban life. Based on 40 interviews from citizens in two rapidly urbanizing cities in mainland China, this paper attempts to investigate how the supply of leisure facilities affects new urban pathology. There are three general findings of this research: (1) First, new urban pathology commonly exists and varies with urban communities. However, it is not significantly influenced by the pace of city life. It is found that the worse prospect the living standards, the more significant the negative impacts of the new urban pathology. (2) Sufficient urban leisure facilities do have positive impacts on relieving psychological pressure of urban dwellers. Apart from these, residents also achieve stress relief from surrounding therapeutic landscapes like aesthetic public space, well-designed architecture, etc. (3) The perceived usefulness of leisure environment serves as a key factor to mediate the stress-mitigating effect of leisure supply. When leisure facilities' functions highly match the needs of residents, leisure environmental supply can be utilized effectively, which helps alleviate the new urban pathology. This research advances the literature of urban health studies by tentatively revealing the interaction between the supply of leisure environmental facilities and urban mental health. It suggests that urban practitioners should optimize the quality of facilities rather than simply increasing the quantity for reducing the daily stress of urban life.

\footnotetext{
${ }^{1}$ School of Tourism Management, Sun Yat-Sen University, Guangzhou, China. ${ }^{凶}$ email: liuyi89@mail.sysu.edu.cn
} 


\section{Introduction}

rban pathology is a medical metaphor derived from a combination of medical science and ancient geometric in the 18th Century that regards the city as a body. Deficient urban symptoms, such as pollution, urban unrest, and problems of social class are viewed as sickness of urban organism (Ostwald and Moore, 2020; Thomsen, 2014). It is akin to the construct Social Pathology, a concept developed to refer both to pathological aspects of social structures and to the behaviors and values attributed to particular social categories, but urban pathology focuses on problems of urban life and social disorganization (Pitcher, 1997). In prior studies, urban problems and disorganization refer to negative impacts posed by urbanization, which can be represented by deteriorating living conditions (Antonia, 1993), high neighborhood density (Choldin, 1978), traffic congestion (Abu, 2009), gentrification and rising crime rate (Jens et al., 2001; Willis, 2000; Mutatkar, 1995), all of which result from the conflict between over-population and limited resource supply. Arising from rapid urbanization, these problems are deemed detrimental to social and economic development (Mutatkar, 1995). Under China's urbanism context, urban pathology refers in particular to structural problems triggered by high-speed urbanization, such as empty housing, population overcrowding, ecological destruction and deteriorating infrastructures (Sorace and Hurst, 2016).

However, the adverse impacts are far beyond physical urban settings and have been triggering a series of health issues such as chronic diseases and psychiatric disorders. For instance, the increasing occurrence of cancer can also be caused by overweight and physical inactivity associated with urbanization and economic development (Jemal et al., 2013). It is also reported that urban life correlates with several mental diseases, which means that a higher exposition to chronic social stress in urban areas can turn into a pathogenic factor (Devylder et al., 2018; Hartig et al., 2014). Therefore, it is necessary to conduct in-depth research on psychological problems brought by urbanism and how to prevent citizens from mental diseases.

The links between built environment and health have long been receiving increasing interest (Handy et al., 2002; Renalds et al., 2010; Guo et al., 2021). Specifically, leisure environment provides citizens with spaces for physical activity and socializing, and such human-environment interactions help improve individuals' well-being (Paggi et al., 2016). Urban green space in particular, as an essential part constituting leisure environment in cities, has been extensively studied concerning its benefits for preventing physical health issues as cardiovascular disease, mental health problems and even mortality (Ewing et al., 2014; Gascon et al., 2016). Notably, theories of Environmental Psychology as Stress Reduction Theory (Ulrich et al., 1991) and Attention Restoration Theory (Kaplan and Kaplan, 1989) have suggested that an exposure to natural environment and green landscape can help reduce psychological stress and facilitate restoration from mental fatigue and negative moods (Jiang et al., 2021). However, in spite of various definitions of green space from multiple disciplines, they have not yet extended to a wider concept of leisure environment (Taylor and Hochuli, 2017). Hence, there is still room for discovering the association between leisure environment and health.

Furthermore, the current literature on urban pathology have yet to unpack new phenomena brought by social changes (Marsella and Pedersen, 2004; Kuddus et al., 2020; Malkoff-Schwartz et al., 2000). Urban dwellers increasingly suffer from constant stress due to the instability and fast pace of urban life (Mayer and Knox, 2009). Current studies on urban problems and health issues are mainly conducted from medical and psychological perspectives (Cruwys et al., 2013; Lund et al., 2011). Although some studies take environment and urban planning into consideration, they did not take a step further into the field of leisure research, nor pay enough emphasis on environmental factors such as the quality, structure and accessibility of urban leisure facilities. Most of them focus on the relationship between urban green space and mental health, while little attention is paid to the leisure environmental supply beyond green space (Collins et al., 2020). Nowadays, citizens not only regard green space as space that helps ease pressure, but also consider commercial and public recreational facilities as their leisure spaces, such as shopping malls, theaters, and libraries. So, it is necessary to take these facilities into consideration to further investigate how leisure environment affects urban residents' mental health.

On account of the above concerns, this research explores two research questions. First, distinguishing from traditional pathological symptoms that reveal crime, social unrest and moral issues, new urban pathology conceptualized in this research attempts to cope with mental health problems, including anxiety, social phobia, depression and so on that disturb modern citizens. Second, this paper explores the characteristics of the pathologies under different urbanism contexts and examines whether leisure facilities and environment would exert and how it exerts positive impacts on relieving new urban pathology. Based on a qualitative method, the paper employed a combination of field research and second-hand official statistics, conducting 40 interviews from four communities in Zhuhai and Guangzhou, China. This effort not only advances urban health studies by conceptualizing a new phenomenon, but also sheds light on potential solutions to alleviate stressors of urban life through optimizing leisure supply in city.

The contribution lies in highlighting the significance of urban mental health and constructing a new concept to integrate fragmented research of urban greenness and mental health to the leisure environment domain, along with distinguishing and extending it from traditionally identified urban pathology. Furthermore, through identifying the impacts of leisure supply on pathological issues associated with urban living, it also creates new research pathways by considering the positive correlation between the quality of leisure space and mental wellness and contributes to the multi-disciplinary studies of urban management and public health.

\section{The rise of new urban pathology and leisure environment supply}

This section examines how urban pathology has been evolving over time and the conceptualization of new urban pathology. Then it reviews studies on the effects of urban leisure environment on improving mental status.

From traditional urban pathology to new urban pathology. The term Urban Pathology is an anthropocentric metaphor that initially stems from a combination of medical science and ancient geometry in the 18th century, created by planners and amateur scientists in order to visualize the complex interactions occurring within cities. Regarding cities as organism and later human body enabled urban planners to diagnose urban symptoms such as pollution, crime and moral degradation etc (Ostwald and Moore, 2020). Whereas, this metaphor had been gradually replaced by Urban Problem and some more specific terms as Density, Pollution, Urban Unrest, etc., after reaching its peak in urban studies in the late 18th century and early 19th century. Thus, discussing studies of urban pathology is in essence discussing urban disorganization and problems affected by urbanism or urban environment with a metaphoric approach. 
Urban disorganization and problems refer to systematic negative impacts on social-economic development brought about by the defects of urbanization (Zhou, 2004), the essence of which is the imbalance of urban economic, social, cultural, and ecological development (Shi, 2014). Urban problems first appeared as public health issues in the early phase of urbanization in European countries around the mid-14th century, due to the lack of necessary infrastructure. Poor sanitation, environmental pollution, and the outbreak of deadly infectious diseases all together triggered a public health campaign (Winslow, 1924). At the same time, since urban renewal lags behind economic and population growth, cities are increasingly confronted with multiple problems such as housing issues (Heraud, 1966), traffic congestion (Arnott et al., 2005), and ecological degradation (ME, 2002; Grimm et al., 2008), which worsens human settlement conditions and makes cities even less livable. Nowadays, gentrification and uneven development have gradually been occurring around the globe, increasing social inequality and intensifying social contradictions.

While the academic discourse on urban pathology and problems focuses on the impacts of urban dysfunction on social, economic, and ecological environments, the traditional urban challenges mentioned above are unable to adapt to the new challenges, notably health and wellbeing of citizens, put forward by social dynamics. Rather than sustaining attention on urban fabric or the health of cities, maybe the discourse should be converted to a more humanistic perspective that focuses on residents' health in urban settings. Over the past two decades, there has been an ongoing swift of urban studies from environment-oriented to people-oriented. Studies examining the relationship between urbanicity, health (Vlahov and Galea, 2002) and 'atypical urban pathology' (Xiang, 2014), have been thriving over the last 20 years, but most of which place more emphasis on physical health (Das et al., 2010) than mental health. The gap between urban living and mental health and wellness has gradually been noticed by some scholars and there have been exploratory works, ranging from the effects of urban upbringing on neural social stress processing (Lederbogen et al., 2011), urbanicity and the causation of psychosis (Van et al., 2004; Lydia and Jim, 2005), to the mediation impacts of green space on depression and perceived general health (Sampson et al., 2020), as well as the benefits of nature connectedness on Mindfulness-Based Stress Reduction (MBSR) and Attention Restoration (Choe et al., 2020; Ulrich et al., 1991; Kaplan and Kaplan, 1989). However, there is a lack of an appropriate term to collectively conceptualize these mentioned psycho-social conditions and even fewer with an emphasis on the influences of urban leisure environment.

The pace of life has been defined as the rate, speed, and "relative rapidity or density of experiences, meanings, perceptions and activities" (Lauer, 1981; Amato, 1983; Werner et al., 1985). Bearing faster pace of life in city than countryside, urban dwellers seem to be exposed to an increase in time pressure and deprivation of time (Keinan et al., 2019). There exist a few studies suggesting the linkage between faster pace of life and higher health risks (Raphal et al., 2018; Goldbach et al., 2020; Mei et al., 2019). Specifically, in China, rural residents migrating to city can be regarded as urban migrants for better employment opportunity as well as welfare, this social group are confronted with a series of environmental 'stressors'. Ethnographic studies have been conducted in Shanghai, China, so as to explore inner migrants mental health, subjectivity and urban spaces, times and affective atmosphere, which also offers inspiration for this study reconsidering urban mental health issues as new urban pathology (Richaud and Amin, 2018, 2019; Amin and Richaud, 2020). On the assumption that fast-paced city life may make citizens to be in a state of constant stress, thereby worsening their physiological and psychological conditions, resulting in a series of modern chronic diseases and mental disorders, the research aims to shed light on the factors affecting the mental wellness of city dwellers under the ongoing process of urbanization. This paper defines new urban pathology as a phenomenon in which the mental health and wellness of residents are negatively affected by factors related to stressful events in urban living. And it analyzes and uncovers the detrimental impacts posed by urbanism on citizens' quality of life from the perspective of psychological health.

Leisure environment, recreational space, and urban stress alleviation. Leisure and recreational activities refer to self-chosen activities consumed by individuals in their free time and deriving physical and mental pleasure, spiritual satisfaction, self-realization, and development that cannot ordinarily be derived from ordinary life affairs (Zhang and Song, 2001; Zhou and Dong, 2004). As for leisure environment, there is no overwhelming consent about a unique definition or classification of leisure environment or recreational space (Tinsley and Eldredge, 1995; Scott and Willits, 1998; Passmore and French, 2001; Lloyd and Auld, 2002). According to three categories of leisure resources supply proposed by Marans and Mohai (1991), 'man-made' (sports-related), 'cultural' and 'natural' resources can be regarded as leisure resources. Besides, urban public spaces are widely considered as leisure spaces (Johnson and Glover, 2013). Specifically, the types of leisure environment proliferate as leisure activities diversify, which includes sports stadium, resorts, shopping mall, entertainment centers, cultural facilities, public spaces like libraries, civil parks and so on (Lloyd and Auld, 2003). It has been widely proven that leisure activities can improve personal perspectives on one's well-being and quality of life (Braj et al., 2011; Pressman et al., 2009). Hectic urbanity and lifestyle changes can impose heavy mental burdens on city dwellers, which may cause non-communicable diseases and mental health problems (Dusica and Lecic-Tosevski, 2019), and leisure environment plays an increasingly crucial role in alleviating the symptoms of these illnesses. For instance, the stress reduction and attention restoration effects of natural environment are widely documented in the mental health geographies literature, suggesting that exposure to nature is beneficial to recover from physiological stress and fatigued attention (Ulrich et al., 1991; Kaplan and Kaplan, 1989). Likewise, studies on the relationship between green space and health show that citizens living in a neighborhood with walkable green space have a lower mortality risk and better perceived general health (Takano et al., 2002; Maas et al., 2006). Green space, parks, and public open space are also believed to benefit mental health through alleviating stress and depression, stimulating physical activity, and facilitating social cohesion (Helbich et al., 2019; McCormick, 2017; Engemann et al., 2019). Given the significance of leisure space, leisure environmental supply is of great importance to urban planning. In general, the classification of urban recreational space can be divided into several types by service type, recreational function, and scope of service, as shown in Table 1 (Xu and Chen, 2018). To be specific, urban leisure spaces can be divided into subjective and subsidiary leisure spaces, active and passive leisure spaces, and different thematic leisure spaces, serving visitors, residents, or targeted groups ( $\mathrm{Li}$ and $\mathrm{Xia}, 2016$ ). In addition, according to the classification of urban recreational spaces mentioned above (Ashman et al., 1999), this research adopts the definition of urban public recreational spaces as both commercial and public urban recreational places for both tourists and residents.

Currently, most research on leisure environment and urban health issues mainly focus on physical space and physical health effects of urbanicity, as well as the links between mental health and urban natural environment. However, there are few papers 
discussing the relationship between psychological health and leisure environment beyond natural landscape. Given that environmental benefits towards mental health are intangible, there remain multiple causative relationships between the leisure environment and health improvement. Furthermore, existing studies relevant to environments and public health are limited to blue-green spaces, with few studies paying attention to the broader leisure environment and public recreational facilities. As urbanization proceeds rapidly in China, new urban pathology has become increasingly apparent and visible. To date, there are few empirical studies on such 'pathology'; insufficient attention is paid to the problem of deficient supply in leisure space. Thus, it is high time to study the influence of urban leisure space over mental health and explore the correlation between the urban leisure supply and the occurrence of new urban pathology.

\section{Case selection and research method}

Selection of cases. Generally, new urban pathology derives from urban-induced stress, which is mainly a natural consequence brought about by the fast pace of life and living conditions in cities. Therefore, in order to qualitatively examine the impact of leisure supply on new urban pathology, it is necessary to compare the cases that demonstrate significant differences in living environment, pace of life and supply of leisure facilities.

Based on the concerns above, four communities were selected, two from Guangzhou and the others from Zhuhai, Guangdong province, China. As for the city selection, the main reason is that the living conditions are of great difference. In 2019, as the provincial capital city and one of the most developed cities in the Pearl River Delta, Guangzhou has a population of 15.3 million and a GDP of 3610.45 billion USD (Guangzhou Municipal Bureau of Statistics, 2019-2020). In the center of Guangzhou, urbanization problems such as traffic congestion, overpopulation, and gentrification are long-standing problems. In contrast, Zhuhai is a special economic zone and also a tourism city with about 3 million population and economic output of 525.00 billion USD in 2019. With the reputation of a romantic city, Zhuhai enjoys fascinating

\section{Table 1 Classification of urban recreational spaces.}

\section{Classification standard Specific type}

Service object $\quad$ Recreation space for local residents

Recreation space for tourists and local residents

Recreational function Commercial recreation space

Self-sustaining recreation space

Public recreation space

Scope of service

Regional recreation space

Urban recreation space

Community recreation space

Indoor recreation space coastal landscape and pleasant climate, illustrating an example of a city with a slower pace of life. In 2018, the green space rate in builtup areas is $48.47 \%$ in Zhuhai and $39.22 \%$ in Guangzhou. The per capita parkland area is $19.9 \mathrm{~m}^{2}$ in Zhuhai and $17.3 \mathrm{~m}^{2}$ in Guangzhou. The number of city parks is 370 in Zhuhai and 247 in Guangzhou (Zhuhai Municipal Bureau of Statistics, 2019-2020; Guangzhou Municipal Bureau of Statistics, 2019-2020). Therefore, Guangzhou is much more developed than Zhuhai, with a much faster pace of urban life and more urbanization problems but less public recreation space, so its urban residents are more likely to suffer severer new urban pathology than those in Zhuhai.

As for the community selection, adequacy of leisure supply is considered. We select two communities with sufficient and insufficient leisure spaces from each city, namely Huacheng and Changgang in Guangzhou, Guantang and Nankeng in Zhuhai. In this paper, environmental leisure supply is defined as both commercial and public-financed urban recreational places within $2 \mathrm{~km}$ from the community only, according to Chang (2007) 's findings of Chinese urban citizens' travel range. The adequacy of leisure supply is measured by the ratio of the number of four kinds of leisure facilities and regional population. Specifically, the leisure facilities include public parks, shopping malls, cultural facilities (i.e. libraries, museums and theaters), and public sports venues. Among them, the number of public parks represents the scale of green space and natural landscape. Shopping mall contains a wide range of leisure facilities, such as cinema, restaurants, and coffee shops, which are common recreational places for urban residents. Cultural facilities include libraries, museums and theaters, serving as active and spiritually edifying leisure places in urban life. Finally, considering doing sports as a significant way to relieve daily stress, public sports venues are also taken into account. According to Baidu Map Statistics and field trip notes, this paper summarized the number of leisure facilities within $2 \mathrm{~km}$ around the community and calculated the quantity of leisure facilities per 10,000 people. As is shown in Table 2, the number of leisure facilities per 10,000 people is 1.95 and 2.06 in Huangcheng and Nankeng community respectively. Meanwhile, the number for Changgang and Guantang is comparatively low, with 1.07 and 0.65 respectively. Hence, Huangcheng and Nankeng are equipped with sufficient leisure supply, while leisure supply in Changgang and Guantang is inadequate. By analyzing and comparing the correlation between leisure supply and new urban pathology in the case communities, this paper aims to explore the effects of leisure supply on new urban pathology under different urbanization context.

An overview of case communities. In this section, basic situation of leisure supply in each community will be introduced. The graphical location and profiles of each community are shown in Fig. 1 and Table 3.

Huangcheng. The Huacheng community is located in the Tianhe CBD of Guangzhou, with the busiest social rhythm (Engemann

Table $\mathbf{2}$ Number of leisure facilities within $\mathbf{2} \mathbf{~ k m}$ around the case Communities.

\begin{tabular}{lllll} 
Type/Unit: number & Huangcheng & Changgang & Nankeng & Guantang \\
\hline Public park & 10 & 2 & 8 & 2 \\
Shopping mall & 15 & 12 & 10 & 2 \\
Cultural facilities & 7 & 2 & 7 & 0 \\
Public sports venues & 4 & 2 & 3 & 3 \\
Total number per 10,000 people & 36 & 18 & 28 & 7 \\
& 1.95 & 1.07 & 2.06 & 0.65
\end{tabular}

Data source: The number of facilities is from both the Baidu Map and field trip note. Regional population statistics is provided by the local neighborhood committees during the field investigation. 


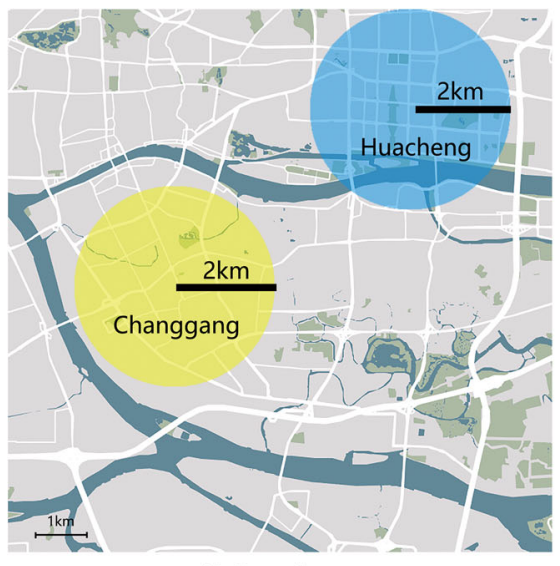

(a) Guangzhou

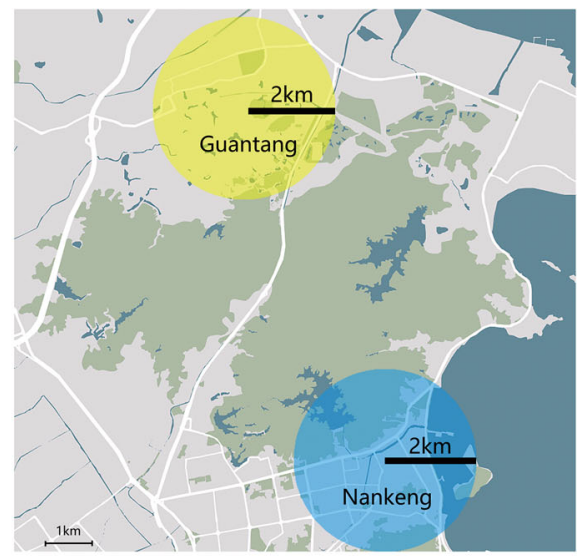

(b) Zhuhai

Fig. 1 Relavtive location of the case communities. Guangzhou is on the left with Changgang and Huacheng community. Zhuhai is on the right with Guantang and Nankeng community.

\section{Table 3 Profiles of communities.}

\begin{tabular}{llll} 
& Huangcheng & Changgang & Nankeng \\
\hline City & Guangzhou & Guangzhou & Zhuhai \\
Location & Urban center & Near center & Urban center \\
Pace of life & Fast & Fast & Slow \\
Leisure supply & Sufficient & Insufficient & Sufficient \\
Number of Interviewee & 10 & 10 & 10 \\
\hline
\end{tabular}

et al., 2019; Li and Xia, 2016) and densest population. With a wide range of high-end service industries gathering around the community, Huangcheng is selected as a case with the fastest pace of life, highest price levels, work intensity, and economic pressure. Dwellers are mostly white-collar and high-income families.

Huacheng has ample public recreational places, including 10 green parks, 1 public plaza, 1 highly popular public library, 2 theaters and 4 museums in Guangzhou, and a wide range of upscale shopping centers such as K11, GTLAND (Autoland) Plaza. These leisure facilities are almost city-level.

Changgang. The Changgang community is situated at the subcenter of Guangzhou. Changgang lacks diversity in the types of leisure facilities. It is only equipped with two small green parks, several shopping centers, for instance, Xiaogang Park, Zhuangtou Park, Guangbai Department Store, Yanhui Plaza. Besides, the recreational facilities in public parks are outdated, mainly serving the middle-aged, the elderly, and children. The cultural and sport facilities are also not sufficient in this area, with only one strictlevel library, 1 museum, 2 sports venues and without any theater.

Nankeng. Nankeng community is in the downtown area of Xiangzhou District, Zhuhai, with a relatively fast pace of life within the city. Nankeng is surrounded by various attractions, equipped with several city-level and community-level public parks, shopping centers, a theater, and coastal sightseeing roads, such as Xiangshan Park, Martyrs' Cemetery, Yangming Plaza, and Zhuhai Grand Theater. Therefore, the public leisure facilities of the surrounding areas are on par with Huacheng.

Guantang. Located in the north of Xiangzhou District, Zhuhai, Guantang community is adjacent to the technology industrial zone, with a slower pace of life, less competitive living environment, and undeveloped local economy. The high-tech industrial zone is mostly populated by white-collar and blue-collar workers in industries such as software, information technology, electronics manufacturing.

The community is a case with scarce public recreational resources. There are only one shopping mall and plaza (Jinding Plaza), two basketball courts, and a football field nearby, the scale of which is relatively small compared with that of Nankeng.

Data collection. Qualitative research methods were mainly used to explore the residents' perception of local leisure environmental supply and investigate the extent of their new urban pathology. Observation was applied to assess actual leisure supply and nonverbal expression of interviewees. Field investigation notes during observation and interview were recorded. Data collected from different sources and the mutual verification can ensure that case studies have good reliability and validity. The paper collects data by three approaches: semi-structured interview, observation and second-hand data.

Semi-structured interview. This research conducted semistructured interviews to collect data from June 2 to July 15, 2019 in the case communities. On-site surveys were carried out around leisure facilities and recreational space in case communities and respondents were selected through non-probability sampling due to the huge population of these communities. In order to ensure the representativeness of the data, the surveys were conducted both on weekdays and weekends. Sample selection is expected to cover as wider age groups as possible, and respondents should be local residents who have lived in the community for more than 5 years. The interview topics mainly include: (1) the respondents' perception of the available urban recreational space (e.g., the size, type, quality); (2) extent of their satisfaction, their frequency of using leisure facilities; (3) their 
recent psychological state (new urban pathology, DAS) and the factors affecting this; (4) the perceived effect of stress alleviation through enjoying these spaces. Each interview lasted from 21 to 45 minutes, the interview process was accomplished when the information was saturated. In total, 51 residents from four communities were interviewed. But six of them refused to answer part of the questions or the length of interview is too short, five participants are not the local community residents. As a result, the valid sample is 40 , who are aged from 19-70 years old and have lived in the selected community for more than 5 years (see details in Table 4a, b). Most of them occupied in different industry and took at least one leisure activity per week in the past half-year.
Given that it is hard for individuals to self-report their mental conditions accurately, we applied "the Depression Anxiety Stress Scale-21" (DASS-21) (Henry and Crawford, 2011; Osman et al., 2012; Lovibond and Lovibond, 1995) in the semi-structured interviews to help measure the residents' mental condition in a more precise way. With the Cronbach's alpha of $0.93(95 \% \mathrm{CI}=0.93-0.94)$ for estimating the reliability (Henry and Crawford, 2005), DASS-21 is an internationally recognized screening tool and one of the most influential psychometric scales used in psychology studies for screening depression, anxiety, and stress. These three indicators are widely believed to represent the mental health condition of a person.

Table 4 Details of (a) samples and (b) case communities.

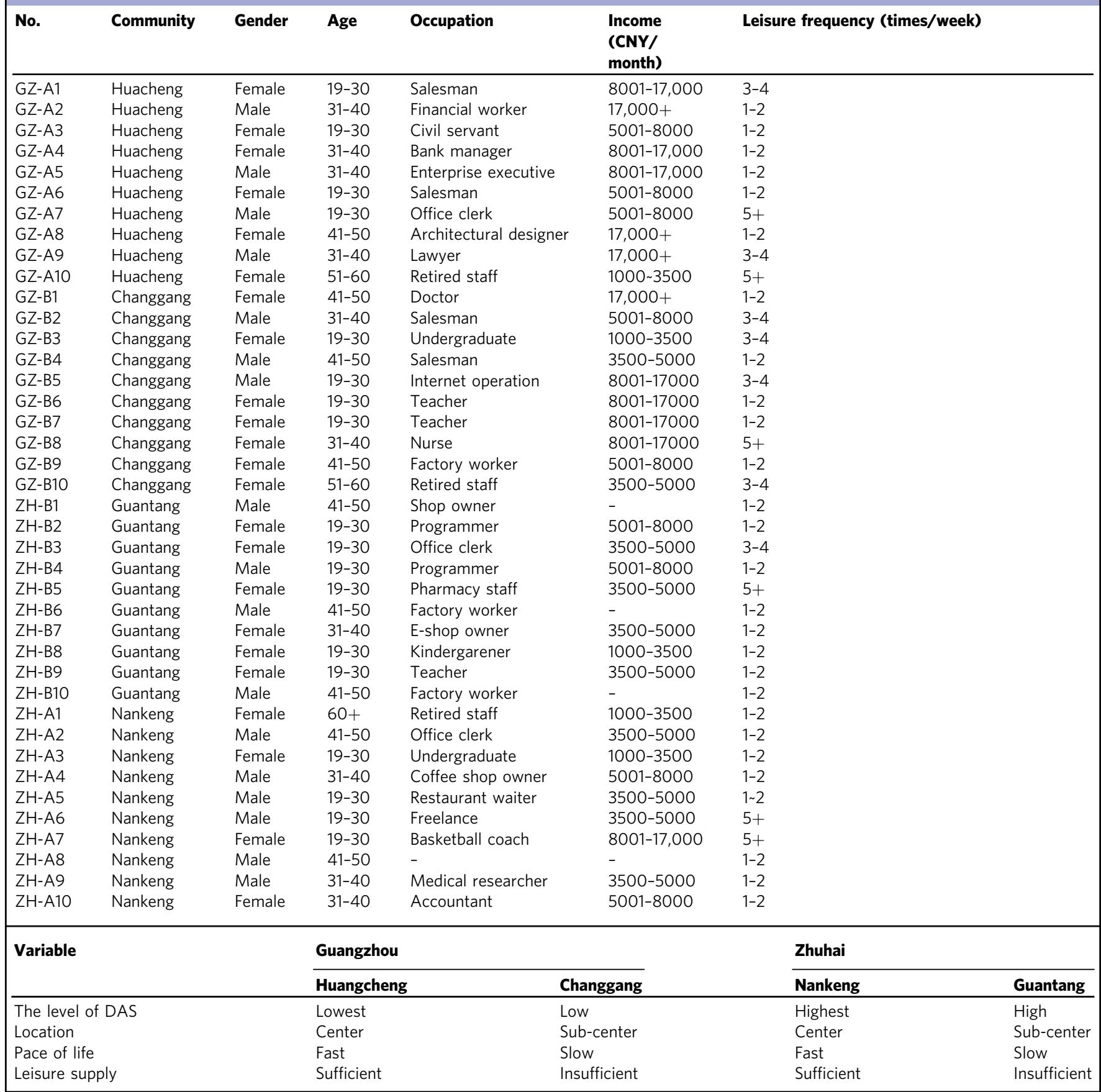


Cognitive mapping. In this research, the perceived and actual leisure environmental supply around the selected communities were both investigated. Chang (2007) discovered that the range of short-distance travel is driven by motivators such as shopping and personal fitness, and short-distance travel is $80 \%$ concentrated within a $2 \mathrm{~km}$ radius around residences. Therefore, we define leisure environment within a radius of two kilometers around the case communities. We first investigated the leisure facilities around the communities through field trips and online map (Baidu Map), then use cognitive map to collect residents' perceived image of the leisure supply.

Cognitive mapping is a complex process by which an individual encodes and stores spatial information, such as through sound, cultural and knowledge about the structural form and elements in space (Crb and Crb, 2019), which is a qualitative method widely used in the research of urban image (Antunes et al., 2020). The hand-drawn map is an important means for mining cognitive maps, which are used to infer people's cognition of space and place. It encourages respondents to draw as much as possible of the objects in a certain geographic area according to his/her memory on a white paper. Participants need to draw out the information such as the location and structural layout of the object features, without requirements for content and form.

In this study, in order to reduce the difficulty of spatial imagination, we give the scope of the area within $2 \mathrm{~km}$ from the community, and stipulate that the participants do not refer to the standard map, and only rely on personal impressions and memories to hand-paint the leisure facilities, and mark the name and location as detailed and accurate as possible. After that, the cognitive frequency ratio of the leisure facilities appearing in the map are calculated (equal to the ratio of the frequency of the facility and the total sample). The leisure facilities with the ratio greater than $20 \%$ are shown in the Fig. 3, which are seemed as the perceived leisure supply by most residents. Later, ArcMap 10.3.1 was used to visualize the statistics of the studied area and to compare the differences between the actual and respondents' perceived leisure supply (see Fig. 3 for details).

Second-hand data. In order to get an insight into cases under different urban contexts, second-hand sources such as economic data reported by news and national statistical yearbooks are taken into account. When visualizing the spatial statistics of cases, cartographic data from Baidu Map is compared with those collected from field investigation for reference.

Data analysis. First of all, individual case analysis for each community is conducted to analyze the basic situation of leisure supply and the degree of new urban pathology of communities based on interviews and DAS questionnaire data (the scoring and calculating process of DASS-21 are shown in Appendix).

Then, cross-case analysis is applied to summarize impacts of leisure supply on new urban pathology and compare the impact patterns under different urban context. By analyzing the similarities and differences between the cases, we make inferences about the research problem and then returns to each case to check if the data supports these inferences. If so, accept it. If not, amend the statement, or specify the conditions that are not consistent. After that, the processed inference is repeatedly compared with the theoretical and textual data in the existing literature.

\section{Results}

Characteristics of new urban pathology and leisure supply in the case communities. Through field investigation, interview, and the DAS survey results, this paper summarizes the important

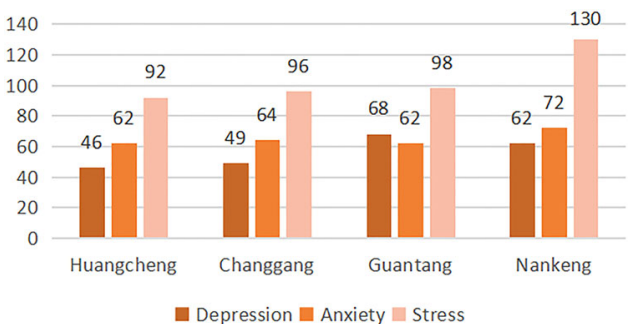

Fig. 2 Differences of the pathology among each community. Here the DAS level presents the pathology of the community residents.

variables in the case communities (see details in Table $4 a, b$ ). As is shown in the table, there is no obvious correspondence between the actual leisure supply and the DAS level of residents. As for each case community, in different cities, communities in similar locations show great differences in the degree of new urban pathology (Fig. 2). Given that Huacheng is located in the center of Guangzhou, the overall DAS level of Huacheng community ranks the lowest $(46,62,92)$, while Changgang community, located in the sub-central area, is slightly higher $(49,64,96)$. By contrast, Nankeng community is also located in the central part of Zhuhai, but its negative psychological state is the most serious (62, 72, 130 ), which is significantly higher than that of the suburban Guantang community $(68,62,98)$.

The following will show residents' perception on leisure facilities and their psychological state according to interview content and analyze the relationship between urban leisure supply and residents' mental state of each community separately.

Huangcheng: sufficient leisure supply, low-level new urban pathology. According to common sense, the residents living in the $\mathrm{CBD}$ of Guangzhou should have a high degree of psychological pressure. However, the level of new urban pathology is relatively low in the community (see details in Table $4 \mathrm{~b}$ and Fig. 2). It is found that the sufficient leisure supply here contributes to the alleviation of psychological stress and leads to a lower level of new urban pathology.

The abundant recreational places cover natural landscapes, culture education, sport and health, entertainment, shopping mall, etc, which can meet diverse needs of urban dwellers when they engage in leisure activities. Thus, the majority of the residents are satisfied with the quality and quantity of the leisure facilities, which serves as an effective alleviating factor for their mental stress. Consequently, the level of each dimension of DAS is relatively low, which leads to lower degrees of new urban pathology around the community. Many interviewees said that a variety of high-quality leisure facilities in their vicinity helped them to relax considerably.

"I think there are enough leisure facilities in Huacheng. There are movie theaters, gyms, coffee shops, and so on nearby. These leisure facilities are of high quality. The environment is quite tidy, the space is also spacious enough, which makes me feel better. Everyday I get off work and go home, I will pass by the Huangcheng square and the riverside park, the amazing night view along the Pearl River and the breeze calm me down. Even if I am not that stressful, I will also come down and walk around because it feels so good." (Sample GZ-A-3 in Huacheng Square, Guangzhou, on 2019.06.05)

"It is nice living near Huacheng Square. For example, when I go to work, under high tension I don't have much time to exercise. There is a gym in the mall next to the company 
(Autoland). I usually run for half an hour every Tuesday and Thursday night. All the dissatisfaction can be vented. On weekend, I would go out for a walk, go to the Provincial Museum to see an Egyptian exhibition, watch a movie or go to the library, which is really relaxing." (Sample GZ-A-2 in Huacheng Square, Guangzhou, on 2019.06.05)

\begin{abstract}
"Although under great pressure at work, the working environment offsets some of the negative emotions. Every time my inspiration dries up, I overlook from the window of the office building. The blue sky, the open river view, and a large green area make people feel very comfortable and less depressed. The quality of the leisure facilities here is quite satisfying. I like to run and climb mountains. When I am upset, I will go for a run (in the park). " (Sample GZ-A9 in Huacheng Square, Guangzhou, 2019.06.08)
\end{abstract}

Changgang: insufficient leisure supply, new urban pathology level slightly higher than that of Huacheng. The pace of life in Changgang is relatively slow, however, local residents' level of new urban pathology is higher than that of Huacheng community located in the CBD area (see details in Table $4 \mathrm{~b}$ and Fig. 2). This may result from the fact that the diversity and quality of the leisure facilities are lower than those in Huangcheng.

Although the community is primarily equipped with two public parks, most interviewees consider this type of leisure space large in scale but with no sense of modernity and aesthetic. So, it is not regarded as their space and the utilization rate of such facilities is low. In addition, for the youth, there is a lack of high-end leisure facilities such as physical training, culture and art, education. In order to meet their needs, some residents have to go to Huacheng or other districts for leisure, which increases the commuting time and creates certain obstacles on their way to recreation. As a result, most of the interviewees in this region said their leisure needs could not be met adequately. There are some respondents whose levels of stress, anxiety, and depression have reached moderate or severe levels. When being asked whether the current status of leisure supply can meet their needs, respondents commented that:

"There are very few leisure facilities nearby, such as Xiaogang Park. If you want to read books, you cannot find any library within this community, you have to go to Zhujiang New Town. And the quality is not satisfying enough. In terms of Xiaogang Park, it is more suitable for the elderly to stroll around, but not for the youth. There are many shopping malls, but they all look the same. I won't feel relaxed just after having a meal or watching a movie now. There is no such kind of commercial pedestrian street or square. I hope there will be more modern green parks or aesthetic commercial complexes, otherwise the community will still be a bit depressing." (Sample GZ-B-2 in Changgang Community, Guangzhou, 2019.06.15)

"It is a densely populated community. When commuting and on weekends, the streets are flooded with people. When I want to find a place of tranquility where I can take a walk and calm down during off days, I cannot find any. For example, there is no seat in Xiaogang Park, and it is more suitable for the elderly and children, but it does not fit the leisure demands of young people. Once I was in a bad mood and went for a walk there, I saw a group of elderly aunts playing music and dancing around. It was quite noisy. I still hope that more modern public spaces or sports facilities can be constructed to offer facilities for us office workers to relax." (Sample GZ-B-7 in Changgang Community, Guangzhou, 2019.06.17)
Nankeng: sufficient leisure supply, high-level new urban pathology. Akin to Huangcheng in Guangzhou, Nankeng is also characterized by a relatively fast pace of life in Zhuhai, surrounded by various leisure facilities. However, most of the respondents felt that there is little place for them to relax and the leisure facilities were insufficient to meet their needs. For example, Xiangshan Park and Martyrs Cemetery mainly target on the elderly and have no appeal to the young. Landmarks like Zhuhai Grand Theater are more regarded as tourist attractions without taking daily recreation of the local as priority. Overall, residents of the Nankeng community agreed that the nearby public recreational space is not consistent with their demands and thus the leisure space there has a low utilization rate, which cannot meet the young and the nine-to-fivers' needs. Although there are sufficient facilities, due to poor matching rate between leisure facilities and demographics, it is still difficult to meet the leisure and relaxation needs of local residents, resulting in higher level of new urban pathology. The residents have relatively high levels of anxiety and stress, and there are several residents with severe stress and anxiety, and mild depression, which makes Nankeng a community with the highest overall psychological stress among all cases.

"Leisure facilities in my perception are very few. There are parks mostly visited by the elderly, due to a large proportion of old people living around. Just for some old ladies to bring children there for entertainment. The younger people seldom go to these places (referring to some parks near the community). For example, I like to taste various wines and coffees, which makes me feel relaxed. But there are few such places here, every time I want to hang out, I have to drive to Gongbei Port, which is quite inconvenient." (Sample ZH-D-4 in Nankeng Community, Zhuhai, 2019.06.23)

"There are many leisure places around, various kinds of parks, and libraries. But for us young office workers, it is relatively monotonous with few options to choose from. Only Yangming Plaza is suitable for recreation." (Sample ZH-D-9 in Nankeng Community, Zhuhai, 2020.06.24)

"Very few, there is not much place to hang out. Take Haiyun City Plaza and the Grand Theater as examples. There are always crowded with people, but they are all tourists. Locals like us don't usually go to these places. Apart from these tourist attractions, only shopping malls like Yangming Plaza are for locals." (Sample ZH-D-10 in Nankeng Community, Zhuhai, 2020.06.24)

Guantang: insufficient leisure supply, high-level new urban pathology. Guantang community is located in the suburban of Zhuhai, with undeveloped local economy and insufficient leisure facilities. Near the technology industrial zone, the community includes numerous factories and white-collar workers. Bars, nightclubs, chess rooms or billiard clubs are leisure places for them to have fun and relieve their stress from intense work. Regarding the quantity and quality of public recreational facilities, most of them asserted that it is insufficient, and they have to go downtown for recreation. It turns out that a number of samples are under immediate or severe stress and anxiety.

"There are few entertainment facilities, with merely a Jinding Plaza, and then there are gyms (privately owned) and yoga studios. There are not much leisure amenities. If you want to go shopping, there is just a small supermarket. 
I hope there can be a bigger commercial plaza in the future. Because if we want to dine out, we have to go far away to Yangming and Huafa Plaza (in downtown)." (Sample ZHB-3 in Guantang Community, Zhuhai, 2019.07.03)

"As a programmer, working in a software company, and typing codes every day, I feel extremely stressful. After work, we would like to find a place to drink, play cards, play billiards, etc. But we have to go to Nankeng for fun. It's too far. Every time I think of this, I get depressed." (Sample ZH-B-4 in Guantang Community, Zhuhai, 2019.07.03)

Impacts of leisure supply on new urban pathology. This section will explore how leisure environmental supply affects new urban pathology by summarizing and comparing the qualitative data and facts from four case communities.

The alleviating effects of leisure supply on new urban pathology. By conducting in-depth case studies of four communities, it is found that sufficient urban leisure facilities are effective in relieving residents' psychological pressure. Notably, leisure environment serves as a platform for residents to participate in interpersonal interaction and recreational activities. Leisure facilities such as sports and health, cultural amenities, and shopping mall have positive effects on alleviating the negative psychological state. Apart from these, residents also achieve stress relief from general therapeutic landscapes like aesthetic urban landscapes, welldesigned architecture, etc.

Firstly, when under great tension, people tend to actively seek out their favorite leisure facilities, and engage in their favorite recreational activities, which has a direct effect on relieving pressure. The involvement of specific leisure activities will help residents temporarily forget their worries, relax themselves and calm down, set themselves free from work, and temporarily refresh themselves. In our cases, Huacheng Community in
Guangzhou provides residents with abundant and diverse leisure facilities, so most of the residents can access to leisure supply easily, thereby the overall DAS level is at the lowest level among all cases. However, in places with a small amount of leisure supply and monotonous type, it is often difficult for residents to release through leisure facilities, and symptoms such as anxiety and depression will worsen over time. This is prominently reflected in the communities of Changgang and Guantang, which shows that it is necessary to provide sufficient leisure facilities so that the residents' new urban pathology can be largely soothed.

Moreover, therapeutic landscapes also help relieve mental pressure in an unconscious way, such as natural landscapes, and streets or architecture with modern design. It is because, in the densely populated, traffic congested, fast-pace urban life, a green, natural and aesthetic public space can provide citizens with visual enjoyment and detach themselves temporarily from routine. Working or living near a well-designed city park or a riverside with fantastic landscape, citizens will get a sense of peace and comfort, even if they do not participate in any leisure activity, their new urban pathology can be relieved, and subjective wellbeing can be improved. As Sample GZ-A-3 responded "Even if I am not that stressful, I will also come down and walk around (along the riverside) because it feels so good". And "Although under great pressure at work, the working environment is good. Every time my inspiration dries up, I overlook from the window of the office building. The blue sky, the open river view, and a large green area make people feel very comfortable and not so depressing.” (Sample GZ-A-10)

Perceived usefulness of leisure supply and its impacts on new urban pathology. Based on the field investigation and manual maps, we summarized and visualized the actual leisure environment and residents' perceived leisure supply in the maps, as shown in Fig. 3. Generally, the perceived supply is less than the actual among all cases, but the gap of them is smallest in Huangcheng Community while the largest in Nankeng Community.
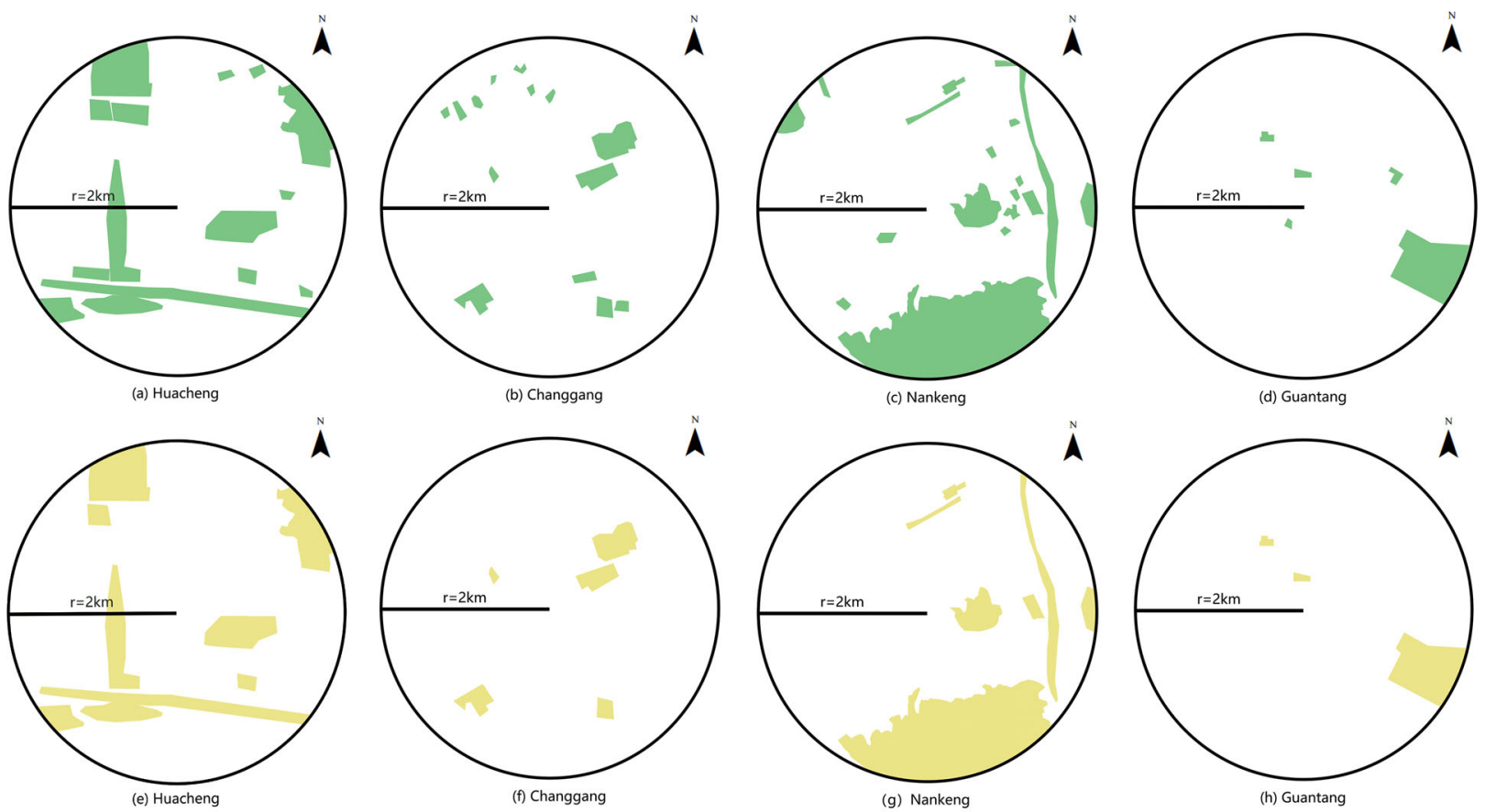

$1 \mathrm{~km}$

Actual Leisure Supply Perceived Leisure Supply

Fig. 3 The results of comparison between actual and perceived leisure supply by communities. Pictures a-d present theactual leisure supply of each community. Pictures $\mathbf{e}-\mathbf{h}$ present the perceived supply of each community. 
This research finds that the perceived usefulness of leisure environment is an essential factor to mediate the stress alleviating effect of leisure supply. The content of perceived leisure environment includes two aspects: the compatibility of the functions and target groups of leisure facilities and the residential leisure demands. When leisure facilities' functions as well as target groups highly match community residents, the usefulness and utilization of leisure environment would be high, which can practically alleviate new urban pathology. The following part analyzes the relationship between perceived leisure environment usefulness and new urban pathology from two aspects: function and target groups.

Firstly, when the functions of leisure environment meet the specific leisure demands of local residents, there are positive effects of leisure supply on negative psychological state. Due to differences in demographic characteristics, different community dwellers' stress type and leisure demands vary significantly. For example, Guantang is located near an industrial area, and the residents are mainly technical staff and factory workers, and their consumption level is mostly medium to low. They need more bars, nightclubs or chess rooms to have fun and relieve their stress from the intense work. However, there is only a public park, two commercial plazas, and an art center in Guantang community, a lack of leisure facilities serve little purpose on relieving their daily stress. Therefore, the new urban pathology is severe in this community. In contrast, Huacheng is located in the CBD, and most of the residents are the white-collar and the middle-class, who have a higher level of consumption and higher requirements for leisure and entertainment facilities, such as well-designed shopping malls, delicate cuisine restaurants, gyms etc. The leisure facilities there are pretty diverse and of high quality, which is perfectly consistent with the local's needs. Therefore, the new urban pathology is relatively low in Huacheng community.

Secondly, high compatibility of leisure supply's target groups and the local community can enhance a sense of leisure identity, thereby improving leisure space utilization and its alleviating impacts on new urban pathology. In the cases of Huacheng and Nankeng, although there are sufficient actual leisure supply, both covering the functions of green landscape, fitness, shopping and entertainment, art and music, education etc. which are all citylevel facilities, Huacheng residents have the lowest DAS level and Nankeng the highest, which is in stark contrast. From Fig. 3, we know that most of the leisure facilities in Nankeng community cannot be perceived and recognized by local residents. The reason lies in the fact that most of the large-scale leisure facilities are city landmarks and mainly designed to attract tourists, like Zhuhai Grand Theater. And green space such as Xiangshan Park is oldfashion and targets on the elderly and children. The local residents feel excluded from the target groups and lose the sense of leisure identity, feeling that such places do not belong to them. Therefore, effective leisure supply that can be perceived in the Nankeng is far less than the actual supply, which leads to the consequence that local residents have insufficient leisure facilities available and find it difficult to relieve pressure.

Urban context, leisure environment and its effects on new urban pathology. New urban pathology are analyzed from the perspective of the whole city, Fig. 4 shows that the overall stress level (S-228) and depression level (D-130) in Zhuhai are much higher than those in Guangzhou (S-188, D-86), and the anxiety level (A) is also slightly higher than that in Guangzhou, which indicates that compared with cases in Guangzhou, residents living in communities in Zhuhai are confronted with a higher risk of psychological problems.

This result is counter-intuitive and different from prior studies: in a developed city with a faster pace of urban life, it should be

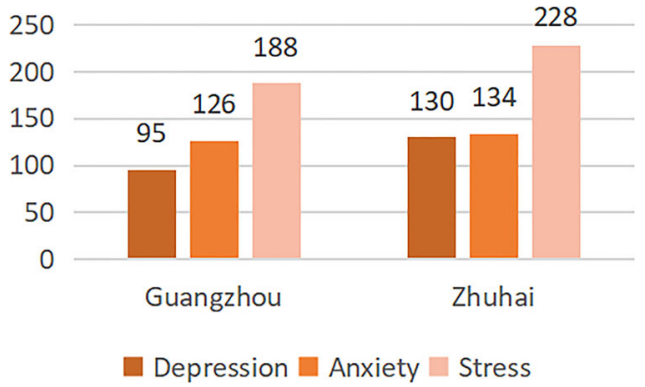

Fig. 4 Differences of DAS between cities. It is obvious that Zhuhai's DAS level is higher than Guangzhou.

more likely for people to feel stressed or anxious. And in a city with leisurely living environment and high quality of life, people tend to feel more relaxed and suffer a lower risk of mental disorder. In this case, while the living environment and life quality in Zhuhai is quite better than that in Guangzhou, city dwellers in Zhuhai still suffer a higher risk of mental illness than the counterpart. It indicates that social rhythm or pace of life cannot sufficiently account for the differences of mental problem in this case. Other factors from the specific urban context might exert impacts on residents' mental health.

According to the analysis of interview materials, it is found that, compared with leisure environmental supply or pace of life, the expectation of urban residents to improve the standard of living has a more significant impact on the new urban pathology. Factors such as income, prospects, and public service facilities play an important role in generating the differences of new urban pathology between Guangzhou and Zhuhai. The impacts of poor development prospect, compared with poor living and leisure environment, on mental health are severer.

Although Zhuhai is well-known for its leisurely pace of life and high-quality living environment in the Pearl River Delta area, due to an enormous amount of tourist immigrants flooding in, the overall level of living expenses in Zhuhai is relatively high compared to a typical Chinese city of the same caliber. However, the level of economic development and per capita income are much lower than that of Guangzhou. Therefore, dwellers in Zhuhai suffer from anxiety associated with greater living costs. The demand to improve the standard of material life intersecting with underdeveloped economy in Zhuhai exerts negative implications on individual psychological state. Apart from the underdeveloped economy, the type of industry in Zhuhai lacks diversity, with mainly small and medium-sized enterprises. It leads to less competitive employment opportunities and salary as well as limited social prospects and personal career. Besides, infrastructure in Zhuhai is not as well-equipped as that in Guangzhou and the quality of medical and educational facilities are weaker than those of Guangzhou, which also serves as an important cause of anxiety for young parents.

"Although Zhuhai is a special economic zone, there are only three upper first-class hospitals. The elderly with serious illnesses can only go to Guangzhou to see a doctor, which makes us worried about the health of the elderly family members"

"There are very few prestigious high schools here in Zhuhai, just Zhuhai No. 1 and No. 2 high schools. These high schools cannot provide platforms for students to enter renowned universities as schools in Guangzhou and Shenzhen. If my children fail to pass the exams, they can only go to very ordinary schools. My child is currently in elementary school, we are anxious and there are plans to 
change jobs to move to Guangzhou, to obtain better education resources for my child."

The interviews above can also be supported by official statistics. In terms of economy development, in 2019, Zhuhai's GDP was 343.589 billion yuan, which was only $14.58 \%$ of Guangzhou's, and its economic and industry scale was also smaller. In terms of price and income level, in 2019, the Total Retail Sales of Consumer Goods in Guangzhou and Zhuhai was 955.157 billion yuan and 123.336 billion yuan respectively; and the permanent population was 15.3059 million and 2.0237 million, which turns out that the per capita social retail consumption in 2019 was 62,400 yuan and 60,936 yuan in Guangzhou and Zhuhai respectively. However, the per capita disposable income of Zhuhai in 2019 was only 52,500 yuan, which is far lower than 65,000 yuan of Guangzhou (Zhuhai Municipal Bureau of Statistics, 2019-2020; Guangzhou Municipal Bureau of Statistics, 2019-2020). The significant gap between per capita consumption level and income level fully demonstrates Zhuhai's urban residents are facing greater pressure on the cost of living.

Above all, the information from various sources demonstrates that only under an urban context with positive prospect, can the stress alleviation impacts of leisure environmental supply on citizens' mental health be more effective.

\section{Conclusion and discussion}

As leisure space plays an increasingly salient role in improving citizens' quality of life, the supply of leisure environment is increasingly instrumental in urban management and city planning. Generally, traditional studies on urban pathology emphasized on the disorganization and structural problems of urbanism and there is insufficient attention paid to mental health of citizens, which emerges from inappropriate urbanization and planning practices. In order to take one step further, this paper conceptualizes new urban pathology to highlight the psychological aspect of urban problems caused by contemporarily highly urbanized life. As a tentative study, this paper offers an insight of how serious the new urban pathology is and how it can be mitigated based on four case studies. Through the case study of four communities under different urban context in Guangzhou and Zhuhai City, the relationship of leisure environment supply and the degree of new urban pathology is uncovered, and the impacts of leisure supply on new urban pathology are explored from the perspective of actual and perceived leisure environment.

There are three main findings in this research. First, new urban pathology widely exists and varies from communities and urban context. However, it is not significantly influenced by the pace of city life. In our case study, the degree of new urban pathology of Guangzhou is much lower than that of Zhuhai. It is apparent that the worse prospect of improving the standard of living, the worse impacts on new urban pathology. Second, sufficient urban leisure facilities do have positive impacts on relieving the pathological state of urban dwellers. When under heavy pressure, people will actively seek out and engage in their favorite recreational activities to relieve pressure. Besides, residents also achieve stress alleviation from therapeutic landscapes such as aesthetic urban landscapes, well-designed architecture, etc. Third, the perceived usefulness of leisure environment serves as a key factor to mediate the stress alleviating effect of leisure supply. When leisure facilities' functions and target groups highly match the needs of residents, leisure environmental supply can be utilized effectively, which helps soothe new urban pathology. In doing so, this paper argues that urban leisure supply can effectively mitigate psychological disorder in front of rapid-living pace or congested urban environment, but the effectiveness is not solely subject to the abundance of supply, but also the psychological perception of the supply and the prospect towards a better urban life.
In terms of the insignificant effect of urban pace of life, this finding is consistent to a paradox raised by Garhammer (2002) that the growing pace of life does not necessarily reduce life satisfaction and happiness. Whereas, a divergence lies in the hypothesis raised by Raphaël Royauté et al. (2018) that faster pace of life would lead to higher health risks and the explanation of the inconsistency may result from the divergent social-economic condition embedded in two cities (Raphal et al., 2018). Another explanation may refer to the finding by Garhammer (2002) that residents living in cities with high pace of life also enjoy more economic opportunities and a wider range of leisure activities which offset the time pressure. As for the relieving impacts of leisure supply on new urban pathology, this finding aligns with the stress reduction and attention restoration effects of current green space literature (Ulrich et al., 1991; Kaplan and Kaplan, 1989), and extends the research scale to a wider context of leisure environment. It also corresponds to studies of environmental psychology and health geography as therapeutic landscape which indicate that both natural elements (Volker and Kistemann, 2015; Wang et al., 2018; Windhorst and Williams, 2015; Kearns and Milligan, 2020) and non-natural elements, such as public libraries or other urban environments (Brewster, 2014; Bornioli et al., 2018), help to heal illnesses. And citizens' preference for aesthetic and demand-matched environment can be explained by their pursuit for high quality spaces (Subiza-Pérez et al., 2019), and the ways citizens use a certain leisure facility also matter. The third finding is out of expectation and it aligns with the latest article by Guo et al. (2021), which indicates that the improvement of subjective well-being is associated with perceived built environment. Also, it can be explained by the relationships between perceived environment and physical activity which are highly related with recreation (Fein et al., 2004; Reis et al., 2009).

The contribution of this research is two-fold. On the one hand, this article innovatively conceptualizes the mental health problems of citizens as new urban pathology so as to distinguish it from previously identified urban problems. This study unpacks an overlooked but increasingly serious issue of urban mental health. As individuals' social status and level of income are unlikely to change dramatically within a short period of time, the issue of maintaining a healthy urban life has become a crucial issue for scholars in both health and urban studies sphere. Specifically, this study attempts to contribute to the multi-disciplinary study of urban management and public health by identifying the impacts of leisure supply on psychiatric issues associated with urban living. It also attempts to integrate the positive correlation between the quality of leisure space and mental wellness, instead of merely discussing the quantity of leisure facilities. The findings of this paper also challenge some traditional views towards urban mental health and environment. These findings alert us to appreciate the differences between actual and perceived utility of leisure space and emphasize a fit between leisure facility's functions and different groups of people's specific leisure demands, which show some possibilities on how we can manage and create better leisure supply when it comes to urban planning. Finally, it highlights several potential ways to improve urban mental health through the optimization of the provision of leisure facilities via mindful urban management and planning.

There are certain limitations to this research. There are already a wide range of studies on green space and mental health, but most of them need to be studied further with repeatable methods, so does this paper (Collins et al., 2020). Specifically, the current conceptualization remains sketchy and in the stage of preliminary definition. The scope of the investigation can be strengthened by improving the sample size. The study can be regarded as an exploratory study into the emerging concept of new urban pathology. Finally, we encourage further investigations to expand the measurable indicators of new urban pathology and supply of 
leisure facilities and analyze the macro panel data of different regions. The dynamics of the quality and quantity of leisure facilities over time should be longitudinally analyzed, along with its corresponding impacts on new urban pathology.

\section{Data availability}

The data that support the findings of this study are available from the corresponding author on reasonable request.

Received: 7 July 2021; Accepted: 8 November 2021;

Published online: 25 November 2021

\section{References}

Abu BM (2009). Urban traffic congestion in Malaysia: under circumstances of rapid urbanization and fast growth of income[J]. J Politics 21-37.

Amato PR (1983) The effects of urbanization on interpersonal behavior. J CrossCult Psychol 14:353-367

Antunes B, March H, Connolly J (2020) Spatializing gentrification in situ: a critical cartography of resident perceptions of neighbourhood change in vallcarca, barcelona. Cities 97:102521

Ashman SB, Monk TH, Kupfer DJ, Clark CH, Myers FS, Frank E et al. (1999) Relationship between social rhythms and mood in patients with rapid cycling bipolar disorder. Psychiatry Res 86(1):1-8

Amin A, Richaud L (2020). Stress and the ecology of urban experience: migrant mental lives in central shanghai. Trans Inst Br Geogr.

Antonia H (1993) Urban air pollution in megacities of the world by the World Health Organization. Geogr Rev 84(1):117

Arnott R, Rave T, Schb R (2005). Alleviating urban traffic congestion. MIT Press Books, p. 1.

Brewster L (2014) The public library as therapeutic landscape: a qualitative case study. Health Place 26:94-99

Bornioli A, Parkhurst G, Morgan PL (2018) The psychological wellbeing benefits of place engagement during walking in urban environments: a qualitative photo-elicitation study. Health Place 53:228-236

Braj A, Ganec A, Merka M, Verko I (2011) Quality of life and leisure activities: how do leisure activities contribute to subjective well-being? Soc Indic Res 102(1):81-91

Chang C (2007) A study on the short-distance travel behavior of urban residents. Beijing Jiaotong University.

Choe EY, Jorgensen A, Sheffield D (2020). Does a natural environment enhance the effectiveness of mindfulness-based stress reduction (MBSR)? Examining the mental health and wellbeing, and nature connectedness benefits. Landsc Urban Plan 202: 103886

Choldin HM (1978) Urban density and pathology. Annu Rev Sociol 4(1):91-113

Crb A, Bcc B (2019) The influence of landmarks and urban form on cognitive maps using virtual reality. Landsc Urban Plan 189:296-306

Cruwys T, Dingle GA, Haslam C, Haslam SA, Jetten J, Morton TA (2013) Social group memberships protect against future depression, alleviate depression symptoms and prevent depression relapse. Soc Sci Med 98:179-186

Collins RM, Spake R, Brown KA, Ogutu BO, Eigenbrod F (2020) A systematic map of research exploring the effect of greenspace on mental health. Landsc Urban Plan 201:103823

Das M, Pal S, Ghosh A (2010) Rural urban differences of cardiovascular disease risk factors in adult asian indians. Am J Hum Biol 20(4):440-445

Devylder JE, Kelleher I, Lalane M et al. (2018) Association of urbanicity with psychosis in lowand middle-income countries. JAMA Psychiatry 75(7):678-686

Dusica, Lecic-Tosevski (2019) Is urban living good for mental health? Curr Opin Psychiatry 32(3):204-209

Engemann K, Pedersen C, Arge L, Tsirogiannis C, Mortensen P, Svenning JC (2019) Residential green space in childhood is associated with lower risk of psychiatric disorders from adolescence into adulthood. Proc Natl Acad Sci USA 116 (11):5188-5193.

Ewing R, Meakins G, Hamidi S, Nelson AC (2014) Relationship between urban sprawl and physical activity, obesity, and morbidity-update and refinement. Health Place 26:118-126

Fein AJ, Plotnikoff RC, Wild TC, Spence JC (2004) Perceived environment and physical activity in youth. Int J Behav Med 11(3):135-142

Gascon M, Triguero-Mas M, Martinez D, Dadvand P, Rojas-Rueda D, Plasencia A et al. (2016) Residential green spaces and mortality: a systematic review. Environ Int86:60-67

Garhammer M (2002) Pace of life and enjoyment of life. J Happiness Stud $3(3): 217-256$
Goldbach C, Hoffmann C, Hoppe J, Pitz T, Thommes K (2020) The fast and the furious-an experimental investigation of the pace of life and risky speed choice in traffic. PLoS ONE 15(7):e0236589. https://doi.org/10.1371/ journal.pone. 0236589

Grimm NB, Faeth SH, Golubiewski NE et al (2008) Global change and the ecology of cities. Science 319: 756-760.

Guangzhou Municipal Bureau of Statistics (2019-2020) Guangzhou Statistical Yearbook. Guangzhou Municipal Bureau of Statistics

Guo Y, Liu Y, Lu S, Chan OF, Lum T (2021) Objective and perceived built environment, sense of community, and mental wellbeing in older adults in hong kong: a multilevel structural equation study. Landsc Urban Plan 209(4):104058

Helbich M, Yao Y, Liu Y, Zhang J, Liu P, Wang R (2019) Using deep learning to examine street view green and blue spaces and their associations with geriatric depression in Beijing, China. Environ Int 126:107-117

Hartig T, Mitchell R, de Vries S, Frumkin H (2014) Nature and Health. Annu Rev Public Health 35(1):207-228

Handy SL, Boarnet MG, Ewing R, Killingsworth RE (2002) How the built environment affects physical activity: views from urban planning. Am J Prev Med 23(2-supp-S1):64-73

Heraud JB (1966) The new towns and London's Housing problem. Urban Studies 3.1:8-21

Henry JD, Crawford JR (2005) The short-form version of the Depression Anxiety Stress Scales (DASS-21): construct validity and normative data in a large nonclinical sample. Br J Clin Psychol 44(2):227-239

Henry JD, Crawford JR (2011) The short-form version of the Depression Anxiety Stress Scales (DASS-21): construct validity and normative data in a large nonclinical sample. Br J Clin Psychol 44(Part 2):227-239

Jens L, Duncan GJ, Paul H (2001) Urban poverty and juvenile crime. Q J Econ 2:2

Jemal A, Bray F, Center MM (2013) Global cancer statistics 2012. CA A Cancer J Clin 65(2):87-108

Jiang B, He J, Chen J, Larsen L, Wang H (2021) Perceived green at speed: a simulated driving experiment raises new questions for attention restoration theory and stress reduction theory. Environ Behav 53(3):296-335

Johnson AJ, Glover TD (2013) Understanding urban public space in a leisure context. Leis Sci 35(2):190-197

Kaplan R, Kaplan S (1989) The experience of nature: a psychological perspective. Cambridge University Press.

Keinan A, Bellezza S, Paharia N (2019) The symbolic value of time. Curr Opin Psychol 26:58-61. https://doi.org/10.1016/j.copsyc.2018.05.001

Kearns R, Milligan C (2020) Placing therapeutic landscape as theoretical development in Health \& Place. Health Place 61:102224

Lauer RH (1981) Temporal man: the meaning and uses of social time. Praeger, New York

Lederbogen F, Kirsch P, Haddad L, Streit F, Tost H, Schuch P et al. (2011) City living and urban upbringing affect neural social stress processing in humans. Nature 474(7352):498

Li H, Xia X (2016) Research progress of urban leisure space abroad. Urban Probl 7:69-74

Lloyd KM, Auld CJ (2002) The role of leisure in determining quality-of-life: issues of content and measurement. Soc Indic Res 57(1):43-71. https://doi.org/ 10.1023/A:1013879518210

Lloyd K, Auld C (2003) Leisure, public space and quality of life in the urban environment. Urban Policy Res 21(4):339-356

Lovibond SH, Lovibond PF (1995) Manual for the depression anxiety \& stress scales, 2nd edn. Psychology Foundation, Sydney

Lund C, Silva MD, Plagerson S, Cooper S, Patel V (2011) Poverty and mental disorders: breaking the cycle in low-income and middle-income countries. Lancet 378(9801):1502-1514

Lydia K, Jim VO (2005) Schizophrenia and urbanicity: a major environmental influence-conditional on genetic risk. Schizophr Bull 4:795-799

Mayer H, Knox PL (2009) Pace of life and quality of life: the slow city charter Springer, Netherlands

Maas J, Verheij RA, Groenewegen PP, Vries SD, Spreeuwenberg P (2006) Green space, urbanity, and health: how strong is the relation? J Epidemiol Community Health 60(7):587-592

Marsella AJ, Pedersen P (2004) Internationalizing the counseling psychology curriculum: toward new values, competencies, and directions[J]. Couns Psychol Q 17(4):413-423

Marans R, Mohai P (1991) Leisure resources, recreation activity, and the quality-oflife. In: Driver B, Brown P, Peterson G eds Benefits of leisure. Venture Publishing, State College, pp. 351-363

Malkoff-Schwartz S, Frank E, Anderson BP, Hlastala SA, Kupfer DJ (2000) Socia rhythm disruption and stressful life events in the onset of bipolar and unipolar episodes. Psychol Med 30(5):1005-16

McCormick R (2017) Does access to green space impact the mental well-being of children: a systematic review. J Pediatr Nurs 37:3-7 
Mei Q, Li C, Yin Y, Wang Q, Wang Q, Deng G (2019). The relationship between the psychological stress of adolescents in school and the prevalence of chronic low back pain: a cross-sectional study in China. Child Adolesc Psychiatry Mental Health 13(1). https://doi.org/10.1186/s13034-019-0283-2.

ME A (2002) Urban growth and environmental degradation: the case of Cairo, Egypt. Cities 19.6:389-400

Mutatkar RK (1995) Public health problems of urbanization. Soc Sci Med 41(7):977

Kuddus MA, Tynan E, Mcbryde E (2020) Urbanization: a problem for the rich and the poor? Public Health Rev 41:1

Osman A, Wong JL, Bagge CL, Freedenthal S, Gutierrez PM, Lozano G (2012) The Depression Anxiety Stress Scales-21 (DASS-21): further examination of dimensions, scale reliability, and correlates. J Clin Psychol 68(12):1322-1338

Ostwald M, Moore J (2020) The science of urban pathology: Victorian rituals of architectural and urban dissection. Australas J Vict Stud 2(1):65-80

Paggi ME, Jopp D, Hertzog C (2016) The importance of leisure activities in the relationship between physical health and well-being in a life span sample. Gerontology 62(4):450-458

Passmore A, French D (2001) Development and administration of a measure to assess adolescents' participation in leisure activities. Adolescence 36(141):67-75

Renalds A, Smith TH, Hale PJ (2010) A systematic review of built environment and health. Fam Commun Health 33(1):68

Pitcher BL (1997). "Urban Pathology" . Sociology, Social Work and Anthropology Faculty Publications. Paper 442.

Pressman SD, Matthews KA, Cohen S et al. (2009) Association of enjoyable leisure activities with psychological and physical well-being. Psychosom Med 71(7):725-732

Raphal R, Berdal MA, Garrison CR, Dochtermann NA (2018) Paceless life? A metaanalysis of the pace-of-life syndrome hypothesis. Behav Ecol Sociobiol 72(3):64

Reis RS, Hino A, Florindo AA, AEz C, Domingues MR (2009) Association between physical activity in parks and perceived environment: a study with adolescents. J Phys Act Health 6(4):503

Richaud L, Amin A (2018) Life amidst rubble: migrant mental health and the management of subjectivity in urban China. Public Cult 32(1):77-106

Richaud L, Amin A (2019) Mental health, subjectivity and the city: an ethnography of migrant stress in Shanghai. Int Health 11(Suppl_1):S7-S13

Sampson L, Ettman CK, Galea S (2020). Urbanization, urbanicity, and depression: a review of the recent global literature. Curr Opin Psychiatry 33.

Sorace C, Hurst W (2016) China's phantom urbanisation and the pathology of ghost cities. J Contemp Asia 46(2):304-322

Scott D, Willits FK (1998) Adolescent and adult leisure patterns: a reassessment. J Leis Res 30(3):319-330

Shi YS (2014) Measurement index system and empirical analysis of China's urban diseases. Econ Geogr: 34(10), 6.

Subiza-Pérez M, Hauru K, Korpela K, Haapala A, Lehvävirta S (2019) Perceived Environmental Aesthetic Qualities Scale (PEAQS) - a self-report tool for the evaluation of green-blue spaces. Urban For Urban Green 126383. https:// doi.org/10.1016/j.ufug.2019.126383

Taylor L, Hochuli DF (2017) Defining greenspace: multiple uses across multiple disciplines. Landsc Urban Plan 158:25-38

Takano T, Nakamura K, Watanabe M (2002) Urban residential environments and senior citizens' longevity in megacity areas: the importance of walkable green spaces. J Epidemiol Community Health 56(12):913-918

Thomsen A (2014) Housing pathology: a new domain or a new name? Working paper 2014-01.

Tinsley HEA, Eldredge BD (1995) Psychological benefits of leisure participation: a taxonomy of leisure activities based on their need-gratifying properties. J Couns Psychol 42(2):123-132. https://doi.org/10.1037/0022-0167.42.2.123

Ulrich RS, Simons RF, Losito BD, Fiorito E, Miles MA, Zelson M (1991) Stress recovery during exposure to natural and urban environments. J Environ Psychol 11(3):201-230

Vlahov D, Galea S (2002) Urbanization, urbanicity, and health. J Urban Health 79(4 Suppl 1):S1-S12

Van OJ, Pedersen CB, Mortensen PB (2004) Confirmation of synergy between urbanicity and familial liability in the causation of psychosis. Am J Psychiatry 161(12):2312-2314

Volker S, Kistemann T (2015) Developing the urban blue: comparative health responses to blue and green urban open spaces in Germany. Health Place 35:196-205

Wang K, Cui Q, Xu H (2018) Desert as therapeutic space: Cultural interpretation of embodied experience in sand therapy in Xinjiang, China. Health Place 53:173-181

Werner CM, Altman I, Oxley D (1985) Temporal aspects of homes: a transactional perspective. In: Altman I, Werner CM (eds) Home environments, vol 8.
Human behavior and environment: advances in theory and research. Plenum, New York, pp. 1-32.

Willis GM (2000) The emergence of crack cocaine and the rise in urban crime rates. Rev Econ Stat 82(4), 519-529.

Windhorst E, Williams A (2015) It's like a different world: Natural places, postsecondary students, and mental health. Health Place 34:241-250

Winslow C (1924) The evolution and significance of the modern public health campaign. Am J Public Health 14(4):343

Xiang CL (2014) "Urban disease" and its treatment in China's urbanization. J Xinjiang Normal Univ (Ed Philos Soc Sci): 035(002), 45-53.

$\mathrm{Xu}$ X, Chen Z (2018) Summary and enlightenment of China's leisure research progress from the perspective of geography. Geogr Geogr Inf Sci 34(05):119-124

Zhou J (2004) Definition of urban diseases, regulations and justice. China Urban Econ 2:30-33

Zhang G, Song R (2001) Research on leisure. Soc Sci 5:17-20

Zhou C, Dong W (2004) A review of domestic research on leisure and recreation in the last ten years. J Guilin Coll Tour 5:5-10

Zhuhai Municipal Bureau of Statistics (2019-2020) Zhuhai Statistical Yearbook. Zhuhai Municipal Bureau of Statistics

\section{Acknowledgements}

This project was financially supported by Social Science Funding (GD20SQ21), from the Guangdong Planning Office of Philosophy and Social Science.

\section{Ethical approval}

This research was approved and funded by the Guangdong Planning Office of Philosophy and Social Science. This research was performed in accordance with the Declaration of Helsinki.

\section{Informed consent}

All of the interview and survey processes in this research received informed consent form the participants. Before the interview and the survey, the principal investigator explained the study and provided participants with the Participant Information Sheet and Consent Forms. Before the interview and the survey, participants' consent was taken using the Consent Form. The researchers ensured that the participants understood the purposes of the research project before proceeding. Participants were permitted to withdraw from the interview and the survey at any time. All of the information and responses were to remain confidential.

\section{Competing interests}

The authors declare no competing interests.

\section{Additional information}

Supplementary information The online version contains supplementary material available at https://doi.org/10.1057/s41599-021-00980-x.

Correspondence and requests for materials should be addressed to Yi Liu.

Reprints and permission information is available at http://www.nature.com/reprints

Publisher's note Springer Nature remains neutral with regard to jurisdictional claims in published maps and institutional affiliations.

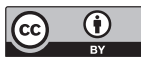

Open Access This article is licensed under a Creative Commons Attribution 4.0 International License, which permits use, sharing, adaptation, distribution and reproduction in any medium or format, as long as you give appropriate credit to the original author(s) and the source, provide a link to the Creative Commons license, and indicate if changes were made. The images or other third party material in this article are included in the article's Creative Commons license, unless indicated otherwise in a credit line to the material. If material is not included in the article's Creative Commons license and your intended use is not permitted by statutory regulation or exceeds the permitted use, you will need to obtain permission directly from the copyright holder. To view a copy of this license, visit http://creativecommons.org/ licenses/by/4.0/.

(C) The Author(s) 2021 